\title{
Combining the Advantages of Powder X-ray Diffraction and NMR Crystallography in Structure Determination of the Pharmaceutical Material Cimetidine Hydrochloride
}

\author{
Abigail E. Watts, ${ }^{\dagger}$ Keisuke Maruyoshi, ${ }^{\ddagger}, \S$ Colan E. Hughes, ${ }^{\dagger}$ Steven P. Brown, \\ and Kenneth D. M. Harris ${ }^{*}{ }^{\dagger}$ \\ ${ }^{\dagger}$ School of Chemistry, Cardiff University, Park Place, Cardiff, Wales, CF10 3AT, United Kingdom \\ "Department of Physics, University of Warwick, Coventry, England, CV4 7AL, United Kingdom \\ ${ }^{\S}$ Analytical \& Quality Evaluation Research Laboratories, Daiichi Sankyo Co. Ltd., 1-12-1, Shinomiya, Hiratsuka-shi, Kanagawa \\ 254-0014, Japan
}

Supporting Information

\begin{abstract}
We report the crystal structure of the anhydrous phase of cimetidine hydrochloride, determined directly from powder X-ray diffraction data. The material was prepared by dehydration of the readily obtained monohydrate form of cimetidine hydrochloride, the only form for which a crystal structure has previously been reported. As such, solid-state dehydration processes typically yield the product phase as a

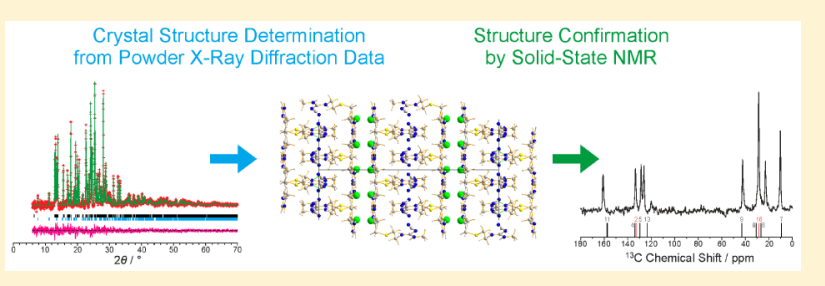
microcrystalline powder, and structure determination was carried out directly from powder X-ray diffraction data, using the direct-space genetic algorithm technique for structure solution followed by Rietveld refinement. The structure determined from powder X-ray diffraction was further validated by calculating solid-state ${ }^{13} \mathrm{C}$ NMR data for the crystal structure (using first-principles periodic DFT techniques within the GIPAW approach) and assessing the quality of agreement with the corresponding experimental solid-state ${ }^{13} \mathrm{C}$ CPMAS NMR data. This strategy provides a robust vindication of the correctness of the crystal structure by assessing the quality of agreement of the structure both with experimental powder X-ray diffraction data and with experimental solid-state ${ }^{13} \mathrm{C}$ NMR data.
\end{abstract}

\section{INTRODUCTION}

Powder X-ray diffraction (XRD) and solid-state NMR spectroscopy are two of the most powerful techniques for characterizing structural properties of polycrystalline samples of organic materials. Within the context of crystal structure determination, the prospects for combining the complementary information provided by these two techniques has the potential to yield more detailed insights than may be obtained from the use of just one of these techniques alone. In particular, determination of a crystal structure directly from powder XRD data ${ }^{1-9}$ followed by calculation of solid-state ${ }^{1} \mathrm{H}$ and ${ }^{13} \mathrm{C}$ NMR chemical shifts [using the GIPAW (Gauge Including Projector Augmented Wave) approach ${ }^{10-14}$ ] for the crystal structure allows a robust independent verification of the correctness of the structure. ${ }^{15-22}$ As such, this combined methodology serves an important role within the wider field of NMR Crystallography. $^{23-26}$

The focus of the present study is the structural properties of the histamine $\mathrm{H}_{2}$ antagonist cimetidine. In pharmaceutical applications, cimetidine is marketed either as the free base or as the hydrochloride salt. In common with many pharmaceuticals, the salt is favored in cases for which rapid dissolution is desired. $^{27}$ The free base form of cimetidine has a high propensity for polymorphism. Based on an FT-IR study, Hegedüs and Görög ${ }^{28}$ list a total of four polymorphs of the free base as well as three distinct monohydrate forms containing the free base, of which the crystal structures of three polymorphs $^{29-31}$ and one monohydrate form ${ }^{32}$ have been reported.

In contrast, the crystal structure of the hydrochloride salt of cimetidine (Figure 1) has never been reported, presumably as a consequence of the challenge of growing a single crystal of this material suitable for single-crystal XRD. Furthermore, we note<smiles></smiles>

Figure 1. Molecular structure of cimetidine hydrochloride showing the atom numbering scheme. Atoms 1 to 5 (with attached hydrogen atoms) constitute the imidazolium ring (note that protonation of cimetidine occurs on the imidazole group). Atoms 10,11, 12, and 15 (with attached hydrogen atoms) constitute the guanidine moiety.

Received: January 5, 2016

Revised: March 4, 2016

Published: March 8, 2016 
that cimetidine hydrochloride has a high propensity to undergo hydration in an ambient atmosphere to form a monohydrate phase (the crystal structure of which has been reported ${ }^{33}$ ). The anhydrous phase of cimetidine hydrochloride may be obtained by solid-state dehydration of the monohydrate phase, although this procedure yields a microcrystalline powder of the anhydrous phase.

In the present paper, we exploit powder XRD, combined with analysis of solid-state NMR data, to determine the crystal structure of the anhydrous phase of cimetidine hydrochloride. Although the task of determining crystal structures from powder XRD data is significantly more challenging than from single-crystal XRD data, particularly in the case of organic molecular materials, advances over the last 20 years or so in the techniques for data analysis are such that it is now feasible to determine the structural properties of organic materials of moderate complexity directly from powder XRD data. ${ }^{1-9}$ In this regard, the direct-space strategy for structure solution has created considerable opportunities and has become the standard approach for tackling structure solution of organic materials from powder XRD data. The prospect of determining crystal structures directly from powder XRD data provides an essential opportunity for structural characterization of organic materials prepared by processes that intrinsically generate microcrystalline powders as the product phase, including (as in the present work) those prepared by solid-state dehydration procedures.

Following determination of the crystal structure of the anhydrous phase of cimetidine hydrochloride from powder XRD data in the present work, first-principles DFT calculations within the GIPAW approach were used to calculate the solidstate ${ }^{13} \mathrm{C}$ NMR data corresponding to the structure, followed by careful scrutiny of the agreement between the calculated and experimental solid-state ${ }^{13} \mathrm{C}$ NMR data. The key feature of this combined strategy is that the quality of the crystal structure determined from the powder XRD data is assessed both against the experimental powder XRD data and against the experimental solid-state NMR data, representing a stringent and robust assessment of the validity and quality of the crystal structure.

\section{EXPERIMENTAL SECTION}

The sample of cimetidine hydrochloride used in this work was purchased from Sigma-Aldrich. Powder XRD data were recorded at 21 ${ }^{\circ} \mathrm{C}$ on a Bruker $\mathrm{D} 8$ instrument (Ge-monochromated $\mathrm{CuK} \alpha_{1}$ radiation) operating in transmission mode. As cimetidine hydrochloride is susceptible to hydration (to form the monohydrate phase), the purchased sample was dried at $100{ }^{\circ} \mathrm{C}$ before packing into capillaries which were then quickly flame-sealed. The capillaries were mounted on a disk sample holder, and two sets of powder XRD data were recorded. The first data set was recorded over $32 \mathrm{~h}$ with $2 \theta$ range 4$50^{\circ}$ and step size $0.017^{\circ}$, while the second data set was recorded over $90 \mathrm{~h}$ with $2 \theta$ range $6-70^{\circ}$ and step size $0.017^{\circ}$.

High-resolution solid-state ${ }^{13} \mathrm{C}$ NMR data were recorded at a magnetic field of $11.7 \mathrm{~T}\left({ }^{13} \mathrm{C}\right.$ Larmor frequency, $\left.125.8 \mathrm{MHz}\right)$ using a Bruker AVANCE III spectrometer. The sample was used as purchased and packed inside a standard solid-state NMR rotor. The spectra were acquired at ambient temperature using ramped ${ }^{1} \mathrm{H} \rightarrow{ }^{13} \mathrm{C}$ crosspolarization $^{34}(\mathrm{CP})$ with a contact time of $1 \mathrm{~ms}$, magic-angle spinning (MAS; spinning frequency, $12.5 \mathrm{kHz}$ ), and ${ }^{1} \mathrm{H}$ decoupling using the SPINAL-64 sequence. ${ }^{35}$ The ${ }^{1} \mathrm{H}$ nutation frequency for both the $90^{\circ}$ pulse and decoupling was $100 \mathrm{kHz}$. The recycle delay was $3 \mathrm{~s}$ and 256 transients were added. The ${ }^{13} \mathrm{C}$ NMR spectra were referenced against L-alanine, with the carboxylate resonance set to $177.8 \mathrm{ppm}$, corresponding to tetramethylsilane (TMS) as the primary reference.
Structure Determination. The two sets of powder XRD data differed in that the first, recorded over the $2 \theta$ range $4-50^{\circ}$, had a lower signal-to-noise ratio, but did not contain any contamination from the monohydrate phase of cimetidine hydrochloride. On the other hand, the second set of powder XRD data, which was recorded over the more extended $2 \theta$ range $6-70^{\circ}$, contained some peaks from the monohydrate phase (due to a small amount of water penetrating the capillary during the period of several months between the two measurements). The first data set was used for indexing and structure solution (benefiting from the fact that this data set was recorded for a monophasic sample of anhydrous cimetidine hydrochloride) whereas the second data set was used for the final Rietveld refinement (benefiting from the fact that this data set extends to a significantly higher maximum value of $2 \theta$ ), with the monohydrate structure added as a "second phase" in the refinement calculations.

The powder XRD pattern of cimetidine hydrochloride was indexed using the DICVOL91 algorithm ${ }^{36}$ in the CRYSFIRE program, ${ }^{37}$ giving the following unit cell with monoclinic metric symmetry: $a=13.63 \AA$, $b=7.66 \AA, c=14.44 \AA, \beta=108.3^{\circ}$. On the basis of density considerations, the number of formula units in the unit cell was deduced to be $Z=4$. Profile fitting using the Le Bail technique ${ }^{38}$ in the program GSAS ${ }^{39}$ could not distinguish unambiguously between several of the primitive monoclinic space groups and independent structuresolution calculations were carried out for nine space groups in this category. The results indicated that $P 2_{1} / a$ is the correct space group. Le Bail fitting for this space group gave a good fit $\left(R_{\mathrm{wp}}=1.65 \%, R_{\mathrm{p}}=\right.$ $1.26 \%$ ) to the powder XRD data (at this stage, using the powder XRD data set recorded over the $2 \theta$ range $4-50^{\circ}$ ).

Structure solution was carried out using the direct-space genetic algorithm (GA) technique ${ }^{40-42}$ incorporated in the program EAGER $^{43-49}$ In the GA structure-solution calculation, the cimetidinium cation was defined by a total of 15 structural variables (3 positional, 3 orientational, and 9 torsional). The chloride anion was defined by 3 positional variables. Each GA structure-solution calculation involved the evolution of 500 generations for a population of 200 structures, with 20 mating operations and 100 mutation operations carried out per generation. For space group $P 2_{1} / a$, a total of 16 independent calculations were carried out, with the same goodquality structure solution obtained in 9 cases.

The best structure solution (i.e., the trial structure with lowest $R_{\text {wp }}$ obtained in the GA calculations) was used as the initial structural model for Rietveld refinement, ${ }^{50,51}$ which was carried out using the GSAS program. Standard restraints were applied to bond lengths and bond angles ${ }^{52}$ and planar restraints were applied to the imidazolium ring and the guanidine moiety. A common isotropic displacement parameter was refined for the non-hydrogen atoms of the cimetidinium cation and a separate isotropic displacement parameter was refined for the chloride anion. No correction for preferred orientation was required. The final Rietveld refinement was carried out using the data set recorded over the $2 \theta$ range $6-70^{\circ}$, with cimetidine hydrochloride monohydrate included as a second phase in the refinement. Le Bail fitting of this set of powder XRD data gave a good fit $\left(R_{\mathrm{wp}}=1.11 \%, R_{\mathrm{p}}=0.82 \%\right.$; Figure 2$)$. The quality of fit obtained in the final Rietveld refinement $\left(R_{\mathrm{wp}}=1.38 \%, R_{\mathrm{p}}=1.01 \%\right.$; Figure 3) was acceptably close to that obtained in the Le Bail fitting procedure on the same data set. From the refined relative scale factor, the proportion of the monohydrate phase in the sample was estimated to be ca. $15 \%$. Final refined parameters for cimetidine hydrochloride: $a=13.6020(6)$ $\AA, b=7.65886(27) \AA, c=14.4257(5) \AA, \beta=108.3724(18)^{\circ}, V=$ $1425.21(14) \AA^{3}\left(2 \theta\right.$ range, $6-70^{\circ}$; 3868 profile points; 141 refined variables).

DFT Calculations. The NMR chemical shifts for the crystal structure of anhydrous cimetidine hydrochloride were calculated using the CASTEP program ${ }^{53}$ (Academic Release version 8.0). First, the crystal structure was subjected to geometry optimization, using a basis set cutoff energy of $700 \mathrm{eV}$, ultrasoft pseudopotentials, ${ }^{54}$ PBE functional, ${ }^{55}$ semiempirical dispersion corrections (TS correction scheme ${ }^{56}$ ), fixed unit cell, preserved space group symmetry and periodic boundary conditions. CASTEP was then used to calculate the chemical shifts, using the GIPAW approach, ${ }^{10-14}$ with a cutoff energy 


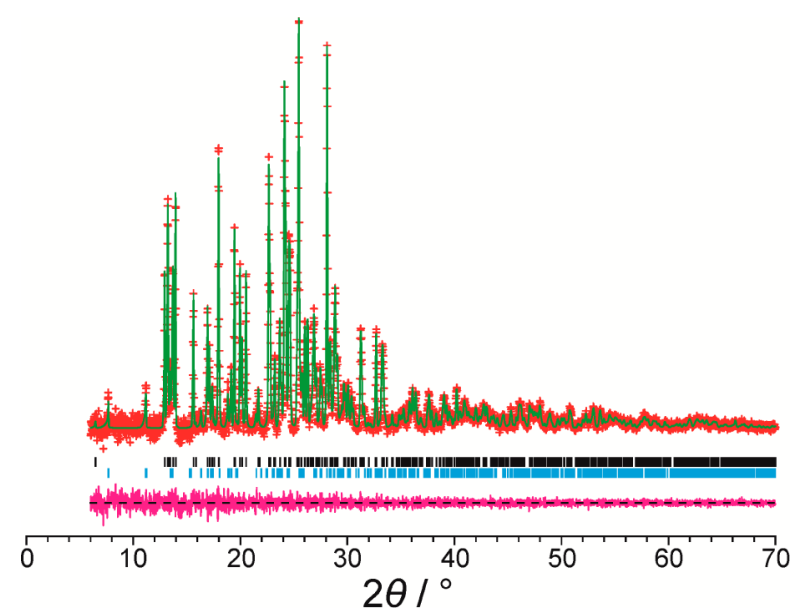

Figure 2. Le Bail fit of the powder XRD pattern (with background subtracted) of anhydrous cimetidine hydrochloride (red + marks, experimental data; green line, calculated data; magenta line, difference plot; black tick marks, predicted peak positions). The blue tick marks represent cimetidine hydrochloride monohydrate, which was added as a second phase in the Le Bail fitting.

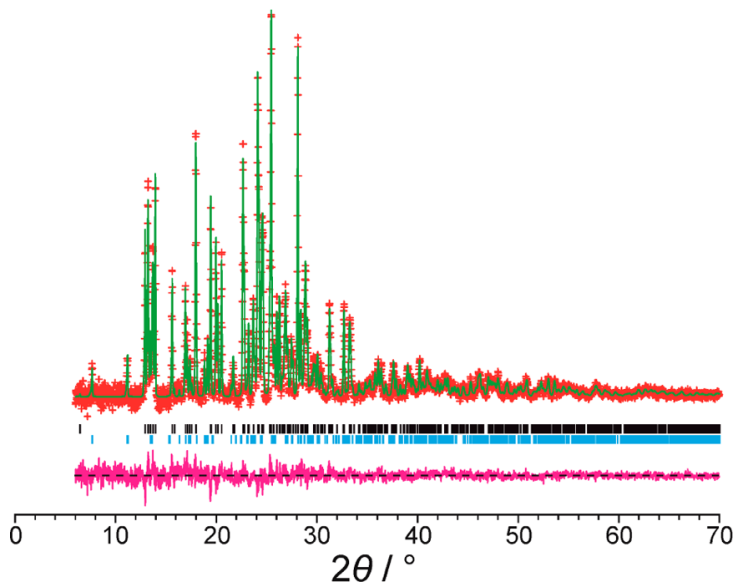

Figure 3. Rietveld refinement for anhydrous cimetidine hydrochloride (red + marks, experimental data; green line, calculated data; magenta line, difference plot; black tick marks, predicted peak positions). The background of the powder XRD pattern has been subtracted. The blue tick marks represent cimetidine hydrochloride monohydrate, which was added as a second phase in the Rietveld refinement.

of $700 \mathrm{eV}$. Both calculations used a Monkhorst-Pack grid $^{57}$ of minimum sample spacing $0.05 \times 2 \pi \AA^{-1}$, for which both types of calculation were found to have converged. Referencing of the ${ }^{13} \mathrm{C}$ chemical shifts was achieved using the formula $\delta_{\text {iso }}($ calc $)=$ $\sigma_{\text {ref }}-\sigma_{\text {iso }}\left(\right.$ calc), where $\sigma_{\text {ref }}$ was determined by adding the mean of the calculated shielding values to the mean of the experimental chemical shifts. ${ }^{12}$ For our calculated and experimental values, this calculation led to a reference value $\sigma_{\text {ref }}=173.8 \mathrm{ppm}$. This method of referencing does not require assignment of the peaks except when two peaks overlap, which occurs in the present case for $\mathrm{C} 2$ and $\mathrm{C} 4$, and for C8 and C16. Additional GIPAW calculations on the anhydrous form of cimetidine hydrochloride and the monohydrate form of cimetidine hydrochloride ${ }^{33}$ are included in Supporting Information. The results from these calculations confirm that the sample analyzed in our experimental solid-state ${ }^{13} \mathrm{C}$ NMR study was indeed the anhydrous form of cimetidine hydrochloride.

\section{RESULTS AND DISCUSSION}

The final refined crystal structure of cimetidine hydrochloride is shown in Figure 4, viewed along the $a$-axis. The structure may be described in terms of slabs parallel to the $a b$-plane, with each slab constructed from the interdigitation of two complementary layers (the two layers are highlighted by yellow and blue shading in Figure 4). Within a single layer (Figure 5), the methylimidazolium moiety of the cimetidinium cation and the chloride anions lie parallel the $a b$-plane and form a zigzag hydrogen-bonded chain that runs parallel to the $a$-axis. This zigzag hydrogen-bonded chain is constructed from the $\mathrm{N}-\mathrm{H} \cdots$ $\mathrm{Cl}^{-} \cdots \mathrm{H}-\mathrm{N}$ motif, involving $\mathrm{N}-\mathrm{H}$ bonds from the methylimidazolium moieties (i.e., $\mathrm{N} 1$ and N3) of two adjacent cimetidinium cations as the donors and an intervening chloride anion as the acceptor. The methylcyanoguanidine parts of the molecule protrude perpendicular to the $a b$-plane and it is these parts of the molecule that are involved in the interdigitation of complementary layers. Within a given layer, a second type of hydrogen-bonded chain runs along the a-axis (Figure 6), specifically a linear array of intermolecular $\mathrm{N}-\mathrm{H} \cdots \mathrm{N}$ hydrogen bonds involving the methylcyanoguanidine parts of adjacent molecules (with $\mathrm{N} 15-\mathrm{H}$ as the donor and $\mathrm{N} 14$ as the acceptor). We note that one $\mathrm{N}-\mathrm{H}$ bond (N10) of the guanidine moiety is not engaged in any hydrogen bonding, and the distance to the nearest potential hydrogen-bond acceptor (the $S$ atom of a neighboring molecule) is $4.17 \AA$.

From the above discussion, it is clear that hydrogen bonding exists only within each layer (see Figures 5 and 6). There is no hydrogen bonding between the two layers that interdigitate with each other to construct a given slab, and there is no hydrogen bonding between adjacent slabs. The interface between adjacent slabs involves the two-dimensional hydrogen-bonded arrays of methylimidazolium moieties and chloride anions that lie parallel to the $a b$-plane. At this interface, the two-dimensional arrays in adjacent slabs are related to each other by an inversion center, which generates an offset between the positions of like charges in the two arrays. Consequently, the shortest $\mathrm{Cl}^{-} \ldots \mathrm{Cl}^{-}$distance at the interface between adjacent slabs is $4.93 \AA$.

The hydrogen-bonding pattern in the anhydrous form of cimetidine hydrochloride reported here is significantly different from that in the monohydrate form. ${ }^{33}$ The monohydrate contains $\mathrm{N} 3-\mathrm{H} \cdots \mathrm{N} 14$ hydrogen bonds between cimetidinium cations together with $\mathrm{N} 12 \cdots \mathrm{H}-\mathrm{O}$ and $\mathrm{N} 15-\mathrm{H} \cdots \mathrm{O}$ hydrogen bonds between cimetidinium cations and water molecules. In addition, the chloride anion is engaged in an $\mathrm{O}-\mathrm{H}^{\prime} \cdot \mathrm{Cl}^{-}$ hydrogen bond involving the water molecule as the donor, and in $\mathrm{N}-\mathrm{H} \cdots \mathrm{Cl}^{-}$hydrogen bonds involving $\mathrm{N} 10$ and $\mathrm{N} 1$ of the cimetidinium cation as $\mathrm{N}-\mathrm{H}$ donors. Consequently, all four $\mathrm{N}-\mathrm{H}$ hydrogen bond donors in the cimetidinium cation are engaged in hydrogen bonding. In contrast, for the anhydrous phase, only three of the four potential $\mathrm{N}-\mathrm{H}$ donors are involved in hydrogen bonding.

The cimetidinium cation has a significantly different conformation in the crystal structures of the anhydrous and monohydrate phases, as evident from the overlay plots in Figure 7. The key conformational difference between the two structures arises around C8, while the moieties at each end of the molecule share very similar conformational characteristics in the anhydrous and monohydrate crystal structures. We note that the substantial difference in molecular conformation between the monohydrate phase and the anhydrous phase 


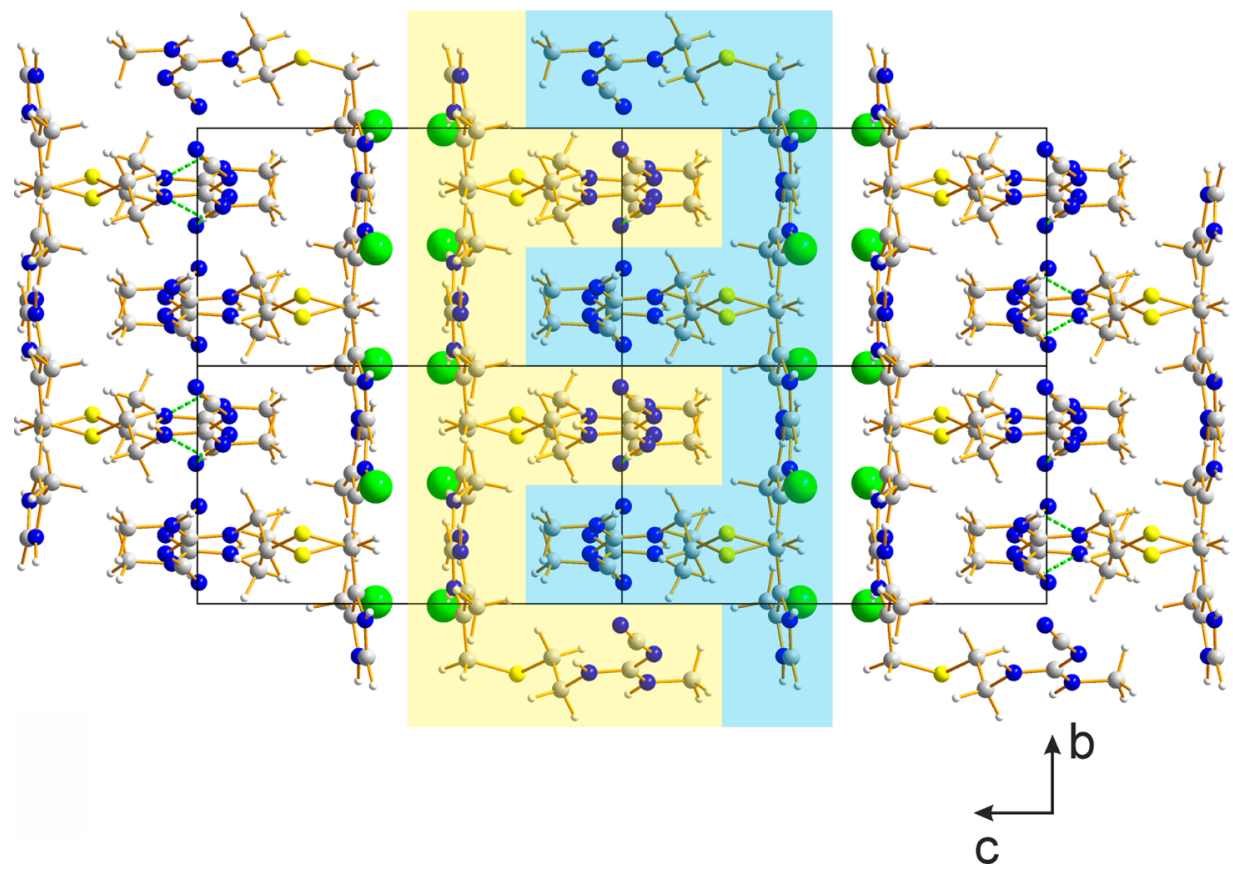

Figure 4. Crystal structure of anhydrous cimetidine hydrochloride viewed along the $a$-axis. The structure is described in terms of slabs parallel to the $a b$-plane, with each slab constructed from two interdigitated layers. In the figure, two layers that interdigitate to form a single slab are indicated by yellow shading and blue shading. Hydrogen bonds are indicated by green dashed lines. Hydrogen bonding exists only within each layer (see Figures 5 and 6 for more details). There is no hydrogen bonding between the two layers that construct a given slab, and there is no hydrogen bonding between adjacent slabs.

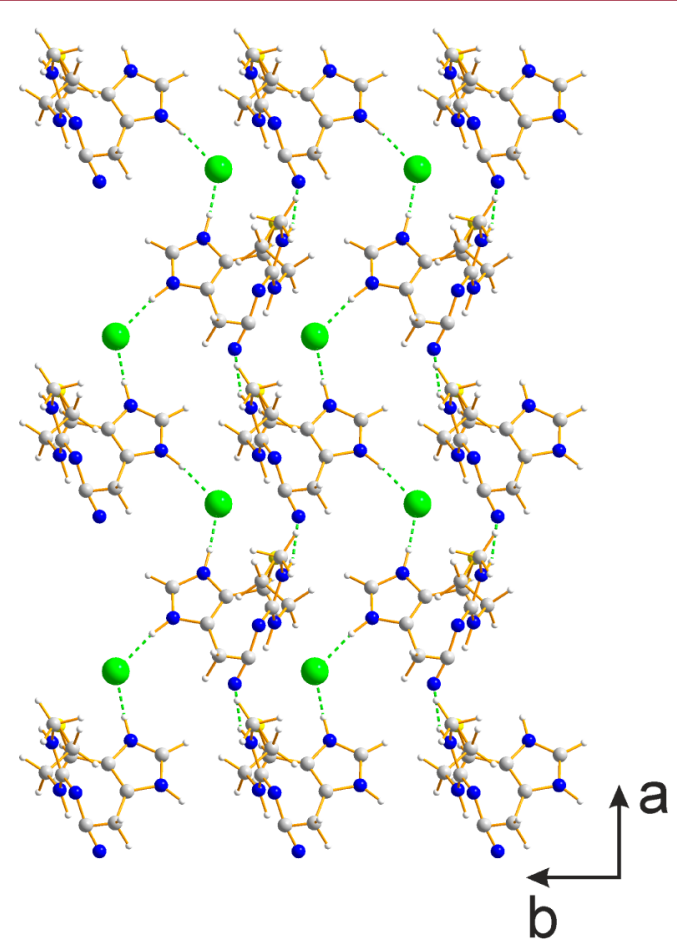

Figure 5. Crystal structure of anhydrous cimetidine hydrochloride showing a single hydrogen-bonded layer parallel to the $a b$-plane. Hydrogen bonds are indicated by green dashed lines. The zigzag hydrogen-bonded chains running along the $a$-axis, constructed from the $\mathrm{N}-\mathrm{H}^{\prime} \cdots \mathrm{Cl}^{-} \cdots \mathrm{H}-\mathrm{N}$ motif (involving two $\mathrm{N}-\mathrm{H}$ bonds of each methylimidazolium moiety and the chloride anions) are clearly evident.

may be a significant factor contributing to the fact that dehydration of the monohydrate phase occurs with loss of

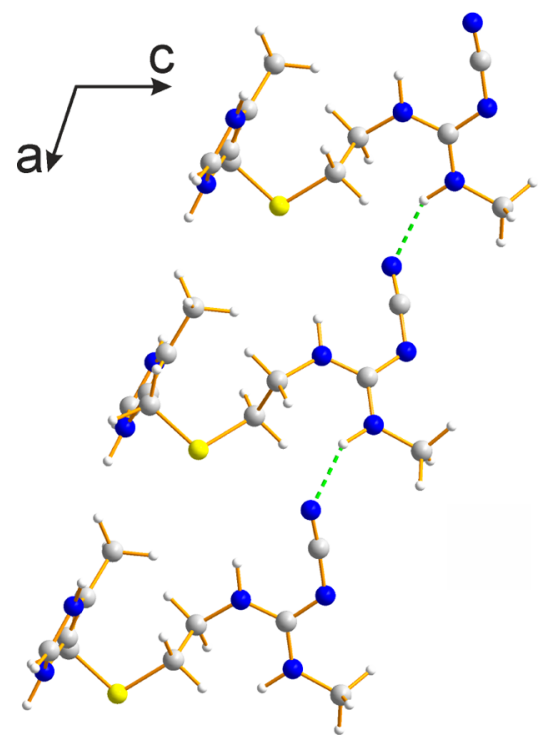

Figure 6. Linear hydrogen-bonded chains (constructed from $\mathrm{N}-\mathrm{H} \cdots \mathrm{N}$ interactions between cimetidinium cations) that run along the $a$-axis in the crystal structure of anhydrous cimetidine hydrochloride. Hydrogen bonds are indicated by green dashed lines.

crystallinity, resulting in a microcrystalline powder sample of the anhydrous phase.

To provide robust validation ${ }^{58}$ of the crystal structure of anhydrous cimetidine hydrochloride determined here from powder XRD data, geometry optimization was carried out using periodic DFT calculations (with fixed unit cell parameters) using the program CASTEP. The optimized structure is very close to that determined from powder XRD data. The maximum displacement for any of the non-hydrogen atoms is 

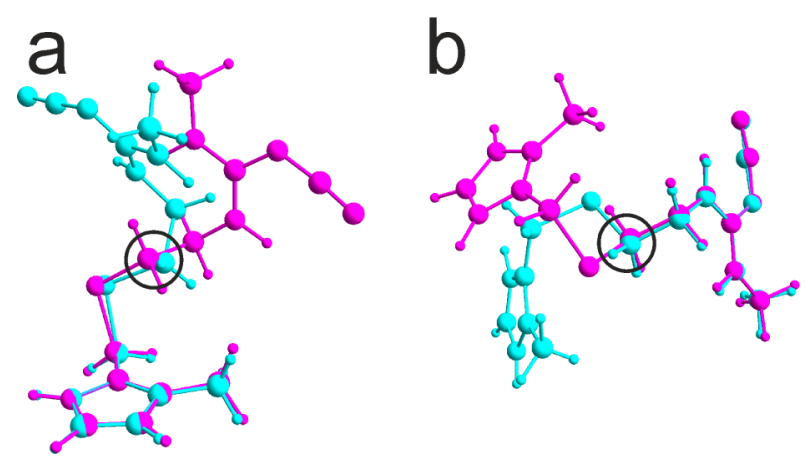

Figure 7. Overlays of the cimetidinium cations in the crystal structures of anhydrous cimetidine hydrochloride (magenta) and cimetidine hydrochloride monohydrate (cyan). In (a) the methylimidazolium moieties are superimposed whereas in (b) the methylcyanoguanidine moieties are superimposed. In each case, the C8 atoms are ringed.

only $0.15 \AA$ (the largest displacements are for $\mathrm{C} 9$ and N10) and the mean atomic displacement is $0.09 \AA$. For the hydrogen atoms, the largest displacement is $0.18 \AA$ for one of the hydrogen atoms in the C8 methylene group. Such close agreement between the structure determined from powder XRD data and the structure obtained following geometry optimization with periodic DFT indicates clearly that the structure determined from powder XRD data is very close to a minimum on the global energy landscape for this molecule with the given unit cell parameters and space group.

To provide additional scrutiny of the correctness of the crystal structure, the isotropic ${ }^{13} \mathrm{C}$ chemical shifts were calculated using the program CASTEP (employing the

Table 1. Calculated (GIPAW) Values of the Isotropic ${ }^{13} \mathrm{C}$ NMR Chemical Shifts $\left[\delta_{\text {iso }}(\right.$ calc $\left.)\right]$ and Experimental Values of the Isotropic ${ }^{13} \mathrm{C}$ NMR Chemical Shifts $\left[\delta_{\text {iso }}(\exp )\right]$ for Cimetidine Hydrochloride

\begin{tabular}{lccc} 
Site & $\delta_{\text {iso }}(\mathrm{calc}) / \mathrm{ppm}$ & $\delta_{\text {iso }}(\exp ) / \mathrm{ppm}$ & $\delta_{\text {iso }}(\exp )-\delta_{\text {iso }}(\mathrm{calc})$ \\
\hline $\mathrm{C} 2$ & 133.0 & 133.3 & 0.3 \\
$\mathrm{C} 4$ & 133.8 & 133.3 & -0.5 \\
$\mathrm{C} 5$ & 129.5 & 128.7 & -0.8 \\
$\mathrm{C} 6$ & 26.8 & 23.0 & -3.8 \\
$\mathrm{C} 7$ & 9.4 & 10.3 & 0.9 \\
$\mathrm{C} 8$ & 30.6 & 28.6 & -2.0 \\
$\mathrm{C} 9$ & 43.1 & 42.3 & -0.7 \\
$\mathrm{C} 11$ & 157.4 & 160.9 & 3.5 \\
$\mathrm{C} 13$ & 123.3 & 126.1 & 2.8 \\
$\mathrm{C} 16$ & 28.3 & 28.6 & 0.3 \\
\hline
\end{tabular}

GIPAW approach ${ }^{10-14}$ ). In Table 1 , the calculated isotropic ${ }^{13} \mathrm{C}$ chemical shifts are compared with those in the experimental high-resolution solid-state ${ }^{13} \mathrm{C}$ NMR spectrum recorded at 11.7 T. Figure 8 shows the experimental ${ }^{1} \mathrm{H} \rightarrow{ }^{13} \mathrm{C}$ CPMAS NMR spectrum of cimetidine hydrochloride together with the peak positions calculated from the DFT calculation. Although there are some small differences, the overall agreement is good and each calculated peak is within $3.8 \mathrm{ppm}$ of the corresponding experimental peak. The largest discrepancies are for C6 (the carbon atom between the imidazolium ring and the sulfur atom) and C11 (the central carbon in the guanidine moiety).

The isotropic ${ }^{13} \mathrm{C}$ NMR chemical shifts calculated for the crystal structure of cimetidine hydrochloride monohydrate (see

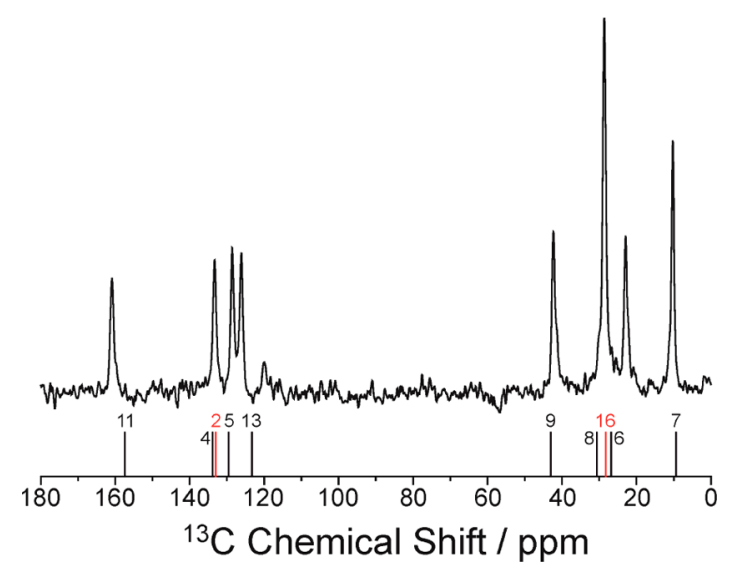

Figure 8. Experimental ${ }^{1} \mathrm{H}(500 \mathrm{MHz}) \rightarrow{ }^{13} \mathrm{C}$ CPMAS $(12.5 \mathrm{kHz})$ NMR spectrum of anhydrous cimetidine hydrochloride. The peak positions calculated for the crystal structure using the GIPAW method are shown below the spectrum (different colors are used simply to distinguish calculated peaks that are in close proximity to each other).

Supporting Information) show significant differences from those observed in the experimental solid-state ${ }^{13} \mathrm{C}$ NMR spectrum reported here (particularly for $\mathrm{C} 6, \mathrm{C} 8, \mathrm{C} 11$, and $\mathrm{C} 13)$, confirming that the sample used for our solid-state ${ }^{13} \mathrm{C}$ NMR measurement was indeed the anhydrous form of cimetidine hydrochloride. Such large differences are not surprising given the distinctly different conformations adopted by the cimetidinium cation in the two crystal structures. We note that close inspection of our solid-state ${ }^{13} \mathrm{C}$ NMR spectrum for the anhydrous form reveals a weak peak at $120 \mathrm{ppm}$ which could potentially be due to a small impurity amount of the monohydrate phase.

\section{CONCLUDING REMARKS}

The crystal structure of anhydrous cimetidine hydrochloride has been determined by taking advantage of the opportunities that now exist for structure determination of organic materials directly from powder XRD data. As cimetidine hydrochloride has a high propensity to undergo hydration in an ambient atmosphere, preparation of the anhydrous phase by a solid-state dehydration procedure meant that only a microcrystalline powder sample was available, necessitating the use of powder XRD data for structure determination. Geometry optimization using periodic DFT calculations and computation of isotropic solid-state ${ }^{13} \mathrm{C}$ NMR chemical shifts for comparison with experimental values provide robust independent verification of the correctness of this structure. While this combined approach involving powder XRD and solid-state NMR has been used previously in structure determination of materials composed of a single type of molecule ${ }^{15-18}$ or neutral cocrystals, ${ }^{19-22}$ the present work represents the first application of this combined methodology in the case of an organic salt. As such materials are common in pharmaceutical applications, we anticipate that this combined powder XRD/solid-state NMR approach will be used extensively in the future in the structural characterization of pharmaceutical materials.

\section{ASSOCIATED CONTENT}

\section{Supporting Information}

The Supporting Information is available free of charge on the ACS Publications website at DOI: 10.1021/acs.cgd.6b00016. 
Supporting Information contains tables and a figure comparing calculated and experimental solid-state ${ }^{13} \mathrm{C}$ NMR chemical shifts (PDF)

Information on the experimental data that supports the results presented in this paper, including the magres output (.magres) files from the CASTEP calculations (containing the magnetic shielding and electric field gradient parameters for all atoms in the crystal structure), together with instructions on how to access this information, can be found in the Cardiff University data catalogue at http://dx.doi.org/10.17035/d.2016. 0008378127

\section{Accession Codes}

CCDC 1445765 contains the supplementary crystallographic data for this paper. These data can be obtained free of charge via www.ccdc.cam.ac.uk/data_request/cif, or by emailing data request@ccdc.cam.ac.uk, or by contacting The Cambridge Crystallographic Data Centre, 12, Union Road, Cambridge CB2 1EZ, UK; fax: +44 1223336033.

\section{AUTHOR INFORMATION}

\section{Corresponding Author}

*E-mail: HarrisKDM@cardiff.ac.uk.

\section{Notes}

The authors declare no competing financial interest.

\section{ACKNOWLEDGMENTS}

We are grateful to Cardiff University for financial support. This project has benefitted from discussions within the framework of the EPSRC Collaborative Computational Project in NMR Crystallography (awards EP/J010510/1 and EP/M022501/1). The $500 \mathrm{MHz}$ solid-state NMR spectrometer used in this research was obtained through the Science City Hydrogen Energy project, with support from Advantage West Midlands. We thank Jonathan Yates for discussions regarding the DFT calculations.

\section{REFERENCES}

(1) Lightfoot, P.; Tremayne, M.; Harris, K. D. M.; Bruce, P. G. J. Chem. Soc., Chem. Commun. 1992, 1012-1013.

(2) Harris, K. D. M.; Tremayne, M.; Lightfoot, P.; Bruce, P. G. J. Am. Chem. Soc. 1994, 116, 3543-3547.

(3) Chernyshev, V. V. Russ. Chem. Bull. 2001, 50, 2273-2292.

(4) Harris, K. D. M.; Tremayne, M.; Kariuki, B. M. Angew. Chem., Int. Ed. 2001, 40, 1626-1651.

(5) Structure Determination from Powder Diffraction Data; David, W. I. F.; Shankland, K.; McCusker, L. B.; Baerlocher, C., Eds.; IUCr/OUP, 2002.

(6) Tremayne, M. Philos. Trans. R. Soc., A 2004, 362, 2691-2707.

(7) Tsue, H.; Horiguchi, M.; Tamura, R.; Fujii, K.; Uekusa, H. Yuki Gosei Kagaku Kyokaishi 2007, 65, 1203-1212.

(8) David, W. I. F.; Shankland, K. Acta Crystallogr., Sect. A: Found. Crystallogr. 2008, 64, 52-64.

(9) Harris, K. D. M. Top. Curr. Chem. 2012, 315, 133-178.

(10) Pickard, C. J.; Mauri, F. Phys. Rev. B: Condens. Matter Mater. Phys. 2001, 63, 245101.

(11) Yates, J. R.; Pickard, C. J.; Mauri, F. Phys. Rev. B: Condens. Matter Mater. Phys. 2007, 76, 024401.

(12) Harris, R. K.; Hodgkinson, P.; Pickard, C. J.; Yates, J. R.; Zorin, V. Magn. Reson. Chem. 2007, 45, S174-S186.

(13) Charpentier, T. Solid State Nucl. Magn. Reson. 2011, 40, 1-20.

(14) Bonhomme, C.; Gervais, C.; Babonneau, F.; Coelho, C.; Pourpoint, F.; Azaïs, T.; Ashbrook, S. E.; Griffin, J. M.; Yates, J. R.; Mauri, F.; Pickard, C. J. Chem. Rev. 2012, 112, 5733-5779.
(15) Filip, X.; Borodi, G.; Filip, C. Phys. Chem. Chem. Phys. 2011, 13, 17978-17986.

(16) Filip, X.; Grosu, I.-G.; Miclăuş, M.; Filip, C. CrystEngComm 2013, 15, 4131-4142.

(17) Li, X.; Bond, A. D.; Johansson, K. E.; Van de Streek, J. Acta Crystallogr., Sect. C: Struct. Chem. 2014, 70, 784-789.

(18) Sardo, M.; Santos, S. M.; Babaryk, A. A.; López, C.; Alkorta, I.; Elguero, J.; Claramunt, R. M.; Mafra, L. Solid State Nucl. Magn. Reson. 2015, 65, 49-63.

(19) Dudenko, D. V.; Williams, P. A.; Hughes, C. E.; Antzutkin, O. N.; Velaga, S. P.; Brown, S. P.; Harris, K. D. M. J. Phys. Chem. C 2013, $117,12258-12265$

(20) Miclaus, M.; Grosu, I.-G.; Filip, X.; Tripon, C.; Filip, C. CrystEngComm 2014, 16, 299-303.

(21) Li, P.; Chu, Y.; Wang, L.; Wenslow, R. M., Jr.; Yu, K.; Zhang, H.; Deng, Z. CrystEngComm 2014, 16, 3141-3147.

(22) Reddy, G. N. M.; Cook, D. S.; Iuga, D.; Walton, R. I.; Marsh, A.; Brown, S. P. Solid State Nucl. Magn. Reson. 2015, 65, 41-48.

(23) Harris, R. K. Solid State Sci. 2004, 6, 1025-1037.

(24) Elena, B.; Pintacuda, G.; Mifsud, N.; Emsley, L. J. Am. Chem. Soc. 2006, 128, 9555-9560.

(25) NMR Crystallography, Harris, R. K.; Wasylishen, R. E.; Duer, M. J., Eds.; Wiley: Chichester, 2009.

(26) For an overview, see the special issue on NMR Crystallography in Solid State Nucl. Magn. Reson. 2015, 65.

(27) Serajuddin, A. T. M. Adv. Drug Delivery Rev. 2007, 59, 603-616. (28) Hegedüs, B.; Görög, S. J. Pharm. Biomed. Anal. 1985, 3, 303313.

(29) Hadicke, E.; Frickel, F.; Franke, A. Chem. Ber. 1978, 111, 32223232.

(30) Párkányi, L.; Kálmán, A.; Hegedüs, B.; Harsányi, K.; Kreidl, J. Acta Crystallogr., Sect. C: Cryst. Struct. Commun. 1984, 40, 676-679.

(31) Arakcheeva, A.; Pattison, P.; Bauer-Brandl, A.; Birkedal, H.; Chapuis, G. J. Appl. Crystallogr. 2013, 46, 99-107.

(32) Kojić-Prodić, B.; Rużić-Toroš, Ž.; Bresciani-Pahor, N.; Randaccio, L. Acta Crystallogr., Sect. B: Struct. Crystallogr. Cryst. Chem. 1980, 36, 1223-1225.

(33) Shibata, M.; Kagawa, M.; Morisaka, K.; Ishida, T.; Inoue, M. Acta Crystallogr., Sect. C: Cryst. Struct. Commun. 1983, 39, 1255-1257.

(34) Metz, G.; Wu, X. L.; Smith, S. O. J. Magn. Reson., Ser. A 1994, 110, 219-227.

(35) Fung, B. M.; Khitrin, A. K.; Ermolaev, K. J. Magn. Reson. 2000, 142, 97-101.

(36) Boultif, A.; Louër, D. J. Appl. Crystallogr. 1991, 24, 987-993.

(37) Shirley, R. The CRYSFIRE System for Automatic Powder Indexing: User's Manual; The Lattice Press: Guildford, U.K., 1999.

(38) Le Bail, A.; Duroy, H.; Fourquet, J. L. Mater. Res. Bull. 1988, 23, 447-452.

(39) Larson, A. C.; Von Dreele, R. B. Los Alamos National Laboratory Report 2004; LAUR86-748.

(40) Kariuki, B. M.; Serrano-González, H.; Johnston, R. L.; Harris, K. D. M. Chem. Phys. Lett. 1997, 280, 189-195.

(41) Habershon, S.; Harris, K. D. M.; Johnston, R. L. J. Comput. Chem. 2003, 24, 1766-1774.

(42) Harris, K. D. M.; Habershon, S.; Cheung, E. Y.; Johnston, R. L. Z. Kristallogr. - Cryst. Mater. 2004, 219, 838-846.

(43) Tedesco, E.; Turner, G. W.; Harris, K. D. M.; Johnston, R. L.; Kariuki, B. M. Angew. Chem., Int. Ed. 2000, 39, 4488-4491.

(44) Albesa-Jové, D.; Kariuki, B. M.; Kitchin, S. J.; Grice, L.; Cheung, E. Y.; Harris, K. D. M. ChemPhysChem 2004, 5, 414-418.

(45) Guo, F.; Harris, K. D. M. J. Am. Chem. Soc. 2005, 127, 73147315.

(46) Guo, F.; Martí-Rujas, J.; Pan, Z.; Hughes, C. E.; Harris, K. D. M. J. Phys. Chem. C 2008, 112, 19793-19796.

(47) Fujii, K.; Lazuen Garay, A.; Hill, J.; Sbircea, E.; Pan, Z.; Xu, M.; Apperley, D. C.; James, S. L.; Harris, K. D. M. Chem. Commun. 2010, 46, 7572-7574.

(48) Fujii, K.; Young, M. T.; Harris, K. D. M. J. Struct. Biol. 2011, 174, 461-467. 
(49) Williams, P. A.; Hughes, C. E.; Harris, K. D. M. Angew. Chem., Int. Ed. 2015, 54, 3973-3977.

(50) Rietveld, H. M. J. Appl. Crystallogr. 1969, 2, 65-71.

(51) McCusker, L. B.; Von Dreele, R. B.; Cox, D. E.; Louër, D.; Scardi, P. J. Appl. Crystallogr. 1999, 32, 36-50.

(52) Standard bond-length and bond-angle restraints were obtained from the mean values of similar structures deposited in the Cambridge Structural Database, as determined using the program Mogul (version 1.7) for bonds between non-hydrogen atoms. Bond-length restraints for bonds involving hydrogen atoms were taken from: Allen, F. H.; Kennard, O.; Watson, D. G.; Brammer, L.; Orpen, A. G.; Taylor, R. J. Chem. Soc., Perkin Trans. 2 1987, S1-S19.

(53) Clark, S. J.; Segall, M. D.; Pickard, C. J.; Hasnip, P. J.; Probert, M. J.; Refson, K.; Payne, M. C. Z. Kristallogr. - Cryst. Mater. 2005, 220, 567-570.

(54) Vanderbilt, D. Phys. Rev. B: Condens. Matter Mater. Phys. 1990, 41, 7892-7895.

(55) Perdew, J. P.; Burke, K.; Ernzerhof, M. Phys. Rev. Lett. 1996, 77, 3865-3868.

(56) Tkatchenko, A.; Scheffler, M. Phys. Rev. Lett. 2009, 102, 073005. (57) Monkhorst, H. J.; Pack, J. D. Phys. Rev. B 1976, 13, 5188-5192.

(58) van de Streek, J.; Neumann, M. A. Acta Crystallogr., Sect. B: Struct. Sci., Cryst. Eng. Mater. 2014, 70, 1020-1032. 